\title{
BMJ Open Socioeconomic status and vitamin D deficiency among women of childbearing age: a population-based, case-control study in rural northern China
}

\author{
Shiqi Lin (D) , ${ }^{1}$ Lifang Jiang, ${ }^{2}$ Yuan Zhang, ${ }^{1}$ Jian Chai, ${ }^{2}$ Jiajia Li, ${ }^{1}$ Xinming Song, ${ }^{1}$ \\ Lijun $\mathrm{Pei}^{1}$
}

To cite: Lin S, Jiang L, Zhang Y, et al. Socioeconomic status and vitamin $\mathrm{D}$ deficiency among women of childbearing age: a population-based, case-control study in rural northern China. BMJ Open 2021;11:e042227. doi:10.1136/ bmjopen-2020-042227

- Prepublication history for this paper is available online. To view these files, please visit the journal online (http://dx.doi. org/10.1136/bmjopen-2020042227).

SL, LJ and YZ contributed equally.

SL, LJ and $Y Z$ are joint first authors.

Received 29 June 2020 Revised 30 December 2020 Accepted 04 March 2021

Check for updates

(c) Author(s) (or their employer(s)) 2021. Re-use permitted under CC BY-NC. No commercial re-use. See rights and permissions. Published by BMJ.

For numbered affiliations see end of article.

\section{Correspondence to}

Professor Lijun Pei; pei_lj@pku.edu.cn and Dr Xinming Song; xmsong@pku.edu.cn

\section{ABSTRACT}

Objective To explore the association between socioeconomic status (SES) and vitamin D deficiency/ insufficiency of women of childbearing age in rural northern China.

Design A population-based, case-control study was conducted.

Setting Four counties of Henan Province, China from 2009 to 2010.

Participants 1151 non-pregnant healthy women between 18 and 40 years old.

Primary and secondary outcome measures Serum 25-hydroxyvitamin D (25(OH)D) levels were measured using high-performance liquid chromatography-tandem mass spectrometry. Vitamin D insufficiency was defined as serum $25(\mathrm{OH}) \mathrm{D} \geq 20 \mathrm{ng} / \mathrm{mL}$ and $<30 \mathrm{ng} / \mathrm{mL}$, deficiency as $\geq 10 \mathrm{ng} / \mathrm{mL}$ and $<20 \mathrm{ng} / \mathrm{mL}$, and severe deficiency as $<10 \mathrm{ng} / \mathrm{mL}$. SES was measured separately by women's and their husbands' education level and occupation, household income and expenditure, as well as aggregately by SES index constructed with principal component analysis.

Results The median serum 25(OH)D level was 20.90 (13.60-34.60) ng/mL, and the prevalence of vitamin $\mathrm{D}$ insufficiency, deficiency and severe deficiency was $20.16 \%, 31.80 \%$ and $15.99 \%$, respectively. After adjustment, household annual income $<¥ 10000$ was associated with increased risk of vitamin $\mathrm{D}$ insufficiency (adjusted OR (aOR): $2.10,95 \% \mathrm{Cl} 1.41$ to 3.14 ), deficiency (aOR: $1.58,95 \% \mathrm{Cl} 1.09$ to 2.29 ) and severe deficiency (aOR: $2.79,95 \% \mathrm{Cl} 1.78$ to 4.38 ); inadequate household income for expenditure was associated with elevated risk of vitamin D insufficiency (aOR: 1.66, 95\% Cl 1.08 to 2.54 ) and deficiency (aOR: $1.81,95 \% \mathrm{Cl} 1.26$ to 2.62 ); low SES index was associated with elevated risk of vitamin D insufficiency (aOR: $2.40,95 \% \mathrm{Cl} 1.52$ to 3.80 ) and deficiency (aOR: 1.64, 95\% $\mathrm{Cl} 1.08$ to 2.50); and both middle and low SES index were associated with increased risk of vitamin D severe deficiency (aOR: $1.70,95 \% \mathrm{Cl} 1.02$ to 2.84 ; aOR: $2.45,95 \% \mathrm{Cl} 1.45$ to 4.14 ).

Conclusions Lower SES was associated with higher risk of vitamin $D$ deficiency/insufficiency in women of childbearing age in rural northern China. More should be

\section{Strengths and limitations of this study}

- Data were population-based and representative and of larger sample size, with information on main exposures and blood samples obtained at the same time to minimise recall bias.

- Both separate dimensions and aggregate index of socioeconomic status were taken to thoroughly examine the association between socioeconomic status and vitamin D status.

- This is one of the few studies to target women of childbearing age in rural northern China, in whom sufficient vitamin D was important both for themselves and for their offspring, but also among whom vitamin $D$ insufficiency/deficiency was found to prevail.

- The level of serum 25-hydroxyvitamin D (25(OH)D) might be underestimated because blood samples in this study were collected in winter, when daylight and temperature were lower compared with summer.

- The laboratory did not participate in any vitamin D standardisation programme or use standardisation of $25(\mathrm{OH}) \mathrm{D}$ measurements, which might affect comparison between the present study and other studies.

done to explore potential mechanisms and to narrow down SES inequalities in vitamin D status.

\section{INTRODUCTION}

Vitamin D deficiency/insufficiency has been a public health concern due to its high prevalence in both developing and developed countries and is linked to occurrences of a variety of chronic diseases and premature mortality. ${ }^{1}$ In China, it is also reported that vitamin D deficiency/insufficiency is common in almost all age groups and areas $^{2}$ and is pertinent to clinical issues besides skeletal problems, such as metabolic syndrome ${ }^{3}$ 
and its complications, ${ }^{4}$ dyslipidaemia, ${ }^{5}$ cardiovascular diseases, ${ }^{6}$ and even emotional, behavioural and attentional problems, ${ }^{7}$ and depression, ${ }^{8}$ as well as reduced sperm quality ${ }^{9}$ and lower total testosterone. ${ }^{10}$ In particular, maternal vitamin D deficiency/insufficiency has been found to be associated not only with adverse gestational and neonatal outcomes such as low birth weight, prematurity $^{11}$ and gestational diabetes mellitus, ${ }^{12}$ but also with offspring vitamin D deficiency, ${ }^{11}$ impaired intrauterine growth, ${ }^{13}{ }^{14}$ type 1 diabetes, nutritional rickets and pneumonia in adulthood. ${ }^{15}$ Although still inconclusive, maternal vitamin $\mathrm{D}$ might begin its vital role in fetal development in the early stage of pregnancy, ${ }^{13}$ suggesting the importance of having adequate vitamin D concentration when preparing for pregnancy. In a word, given that sufficient vitamin status is so vital to women themselves and their offspring and that serum 25-hydroxyvitamin D $(25(\mathrm{OH}) \mathrm{D})$ concentrations were found low among them ${ }^{3}$ and their newborn babies in Chinese populations, ${ }^{2} 1617$ it is of significance to target the vitamin D status and its influencing factors in women of childbearing age.

Since inadequate sunlight exposure and absorption of vitamin $\mathrm{D}$ are among the major causes of vitamin $\mathrm{D}$ deficiency/insufficiency, ${ }^{18}$ a series of studies have indicated vitamin D deficiency/insufficiency follows a gradient of socioeconomic status (SES), ${ }^{19-23}$ a crucial factor that determines one's lifestyle. Even though SES may not be itself a direct causal factor for health problems, exploring social inequalities in vitamin $\mathrm{D}$ deficiency/insufficiency can help to provide clues to the actual mechanisms involved. ${ }^{24}$ However, prior studies on this topic were mostly descriptive, based mainly on findings from Western and West Asian countries, where the distribution of lifestyle in different SES is very distinct from that in other countries such as China. Moreover, previous research on the association between SES and vitamin D deficiency/ insufficiency often focused on elderly and children, and seldom on women of childbearing age. Therefore, the aim of our study was to explore the association between SES and vitamin D deficiency/insufficiency among women of childbearing age in rural northern China, where the prevalence of vitamin D deficiency/insufficiency may be higher than in regions of lower latitude and in more developed economy. ${ }^{2}$

\section{MATERIALS AND METHODS}

\section{Study design and population}

This was a population-based, case-control study. The data of the present research were based on the Study on Population-based Birth Defects Monitoring and Comprehensive Intervention Project, which aimed to establish a prospective cohort of married but unpregnant women of childbearing age in 2009-2010 in Henan Province, collect their baseline characteristics including basic demographic and socioeconomic characteristics, dietary intake and behavioural factors, as well as blood samples, and follow them until pregnancy results were observed so as to explore the association between prepregnancy risk factors and pregnancy results. A multistage cluster sampling method was used to obtain a representative sample of the targeted population. In the first stage, four counties (Hui County, Mengzhou County, Xinmi County and Luanchuan County, the latitudes of which are $35^{\circ} 17^{\prime}$ $\mathrm{N}, 34^{\circ} 50^{\prime} \mathrm{N}, 34^{\circ} 32^{\prime} \mathrm{N}$ and $35^{\circ} 51^{\prime} \mathrm{N}$, respectively) were randomly selected from 158 counties in Henan Province. In the second stage, 40 towns (the next administrative unit below county) were randomly selected from the four counties. In the third stage, five villages were randomly selected from each town. In the fourth stage, 10 women of childbearing age and their husbands were randomly selected from each village. The selection criteria were (1) married women with local permanent residency, (2) between 18 and 40 years old, (3) not currently pregnant, (4) living in the research counties with local registered permanent residency, and (5) without any severe heart, liver, kidney, metabolic diseases, blood or other system diseases or cancers. Finally, 1151 of 2000 women had pregnancy outcomes and were thus included in the project. In our study, cases were defined as women with serum $25(\mathrm{OH}) \mathrm{D}<30 \mathrm{ng} / \mathrm{mL}$ and were further subdivided into three groups: (1) vitamin D insufficiency: serum $25(\mathrm{OH}) \mathrm{D} \geq 20 \mathrm{ng} / \mathrm{mL}$ and $<30 \mathrm{ng} / \mathrm{mL}$; (2) vitamin $\mathrm{D}$ deficiency: serum $25(\mathrm{OH}) \mathrm{D} \geq 10 \mathrm{ng} / \mathrm{mL}$ and $<20 \mathrm{ng} / \mathrm{mL}$; (3) vitamin D severe deficiency: serum $25(\mathrm{OH}) \mathrm{D}<10 \mathrm{ng} /$ $\mathrm{mL}$. Controls were those with serum $25(\mathrm{OH}) \mathrm{D} \geq 30 \mathrm{ng} /$ $\mathrm{mL}$. Altogether, there were 369 controls and 782 cases, among whom 232 had vitamin D insufficiency, 366 had deficiency and 184 had severe deficiency.

\section{Collection of data and blood sample}

Trained healthcare workers conducted face-to-face interviews with participants and their families at baseline to collect information on women's and their husbands' demographic and social economic characteristics, history of adverse pregnancy outcomes, women's history of diseases and treatment, eating habits and frequency of dietary and nutrient intake, behavioural factors, environmental factors, and utilisation of public health services.

For each participant, a fasting venous blood sample $(8 \mathrm{~mL})$ was also collected at baseline by professional healthcare workers. Collection of blood samples was done in December 2009 and in January and February 2010. The sample was prepared by centrifugation and stored at $-80^{\circ} \mathrm{C}$ at Peking University until analysis.

Written informed consent was obtained from all participants before completing the questionnaire and collection of blood samples at the time of the baseline survey.

\section{Measurement of vitamin D status}

Serum $25(\mathrm{OH}) \mathrm{D}$ concentration is the parameter of choice for assessment of vitamin D status. Serum 25-hydroxyl vitamin $\mathrm{D}_{3}$ concentrations in the blood samples of 1151 women were quantitatively determined by highperformance liquid chromatography-tandem mass spectrometry (Ultimate 3000-API 3200 Q TRAP) method to 
overcome inaccuracy problems associated with immunoassays and protein binding assays. ${ }^{25}$ Vitamin D severe deficiency was defined as serum $25(\mathrm{OH}) \mathrm{D}<10 \mathrm{ng} / \mathrm{mL}$, vitamin $\mathrm{D}$ deficiency as $\geq 10 \mathrm{ng} / \mathrm{mL}$ and $<20 \mathrm{ng} / \mathrm{mL}$, and vitamin D insufficiency as $\geq 20 \mathrm{ng} / \mathrm{mL}$ and $<30 \mathrm{ng} / \mathrm{mL}$. ${ }^{26}$

\section{Definition of SES}

In our study, SES was measured by both separate and aggregate indicators. There were six separate dimensions of SES: women's education level, their husbands' education level, women's occupation, their husbands' occupation, household annual income and whether their annual income was enough for expenditure. Women's or husbands' education level was grouped into 'high school or above' and 'junior high school or below'. Women's and husbands' occupation was grouped into 'unemployed or farmers' and 'other occupations'. Household annual income was grouped into ' $\geq ¥ 1000$ ' and ' $\angle ¥ 1000$ '. Household income for expenditure was measured by the question 'whether your family have enough income for expenditure in your daily life?' and we grouped the answers 'a lot more income than expenditure', 'a little more income than expenditure' and 'balanced' into 'surplus', and 'income is not enough for expenditure' and 'a lot more expenditure than income' into 'inadequate or deficit'.

Aggregating over these six dimensions of SES, we further constructed an SES index using principal component analysis. To make the categorical form of data meet the requirement for principal component analysis, all the six categorical variables were coded into binary ones. Since all data have an equal weight, the covariance matrix was used and the Bartlett's test of sphericity was statistically significant $(\mathrm{p}<0.001)$, indicating it is suitable to use principal component analysis here. The first principal component was taken as a measure of SES index, ${ }^{27}$ accounting for $29 \%$ of total variation. This percentage, although it does not seem high, is in accordance with previous studies, ${ }^{28}$ reflecting that correlations between variables were complex and that each variable may have its own determinant other than SES. ${ }^{27}$ The SES index was then divided into three subgroups, namely high, middle and low SES, with the 33rd and 66th percentiles as the cut-off points.

\section{Covariates}

A number of possible confounding factors were also assessed, including demographic variables, nutritional factors, behavioural factors and utilisation of health services.

Demographic variables included age, body mass index (BMI), gravidity and history of chronic diseases. BMI was calculated by weight $/$ height $^{2}$ and was grouped into normal weight or underweight $\left(<24 \mathrm{~kg} / \mathrm{m}^{2}\right)$, overweight $\left(\geq 24 \mathrm{~kg} / \mathrm{m}^{2}-28 \mathrm{~kg} / \mathrm{m}^{2}\right)$ and obese $\left(\geq 28 \mathrm{~kg} / \mathrm{m}^{2}\right) .{ }^{29} \mathrm{We}$ defined history of chronic diseases as having been diagnosed of any one of the following diseases: anaemia, hypertension, hyperlipaemia, heart disease, diabetes, hyperglycaemia, thyroid diseases, phenylketonuria, epilepsy, asthma, chronic renal diseases, systemic lupus erythematosus, rheumatic arthritis, deep vein thrombosis, cancer, depression or anxiety, and schizophrenia.

Nutritional factors included nutritional supplement, meat intake, fish intake, egg intake, milk or dietary product intake, beans and soy product intake, and vegetable intake. Nutritional supplement was evaluated by having taken any of the following during the past month: vitamin $A$, multivitamin $B$, vitamin $B_{1}$, vitamin $B_{2}$, vitamin $\mathrm{B}_{6}$, vitamin $\mathrm{B}_{12}$, vitamin $\mathrm{C}$, vitamin $\mathrm{E}$, cod liver oil or vitamin $\mathrm{D}$, iron preparations, calcium tablets, and zinc supplements. Food intake was measured by the average frequencies of food intake during the past year. The frequencies included 'every day', '4-6 times per week', '1-3 times per week', '1-3 times per month' and 'hardly ever', and were divided into two to three groups according to distribution of the answered frequencies of different food.

Behavioural factors included picky eating habits, passive smoking and physical exercises. Picky eating habits were measured by the question 'do you have picky eating habits, that is, having preferences to some special food such as fruit and vegetables and keeping eating them every day while rejecting other kinds of food such as meat?' Passive smoking was defined as 'being passively inhaled cigarette smoke by smokers around you for more than 15 minutes every day'. Taking physical exercises meant taking any one of the following indoor or outdoor exercises at least once a week for more than $30 \mathrm{~min}$ per time: walking, running, ball games, t'ai chi or other health-promotion physical exercises, swimming and other sports.

Utilisation of health services included accepting eugenic publicity and accepting physical examination during the past year. Having accepted eugenic publicity was defined as having received materials (like brochures) from health service institutions during the past year about knowledge of eugenics such as how to prepare for pregnancy. Having accepted physical examination during the past year was defined as having received systematic inspection of the body for signs and symptoms of disease or abnormality during the past year.

\section{Statistical analysis}

Univariate analysis was conducted to test the differences in vitamin $\mathrm{D}$ status across different demographic characteristics, SES, nutritional variables and utilisation of public health services through $\chi^{2}$ test.

To better identify the relationship between SES and vitamin $\mathrm{D}$ status, we examined the associations between vitamin D status and separate dimensions of SES, as well as the associations between vitamin D status and SES index. Six multivariate logistic regression models were performed in this study to explore (1) the association between vitamin D insufficiency and separate dimensions of SES, that is, women's and their husbands' education and occupation and household annual income and enough annual income for expenditure; (2) the association between vitamin D insufficiency and SES index; 
Table 1 Serum 25(OH)D distribution among women of childbearing age

\begin{tabular}{lccl}
\hline $\begin{array}{l}\text { Serum } \\
\text { 25(OH)D* }\end{array}$ & $\mathbf{n}$ & \multicolumn{1}{l}{$\begin{array}{l}\text { Median (25\%-75\%) (ng/ } \\
\mathrm{mL})\end{array}$} \\
\hline Sufficient & 369 & 32.06 & $40.20(35.10-47.50)$ \\
Insufficient & 232 & 20.16 & $24.35(22.03-26.88)$ \\
Deficient & 366 & 31.80 & $15.40(13.30-17.60)$ \\
$\begin{array}{l}\text { Severely } \\
\text { deficient }\end{array}$ & 184 & 15.99 & $5.63(3.24-7.78)$ \\
Total & 1151 & 100 & $20.90(13.60-34.60)$ \\
\hline
\end{tabular}

*Sufficient: $\geq 30 \mathrm{ng} / \mathrm{mL}$; insufficient: $\geq 20 \mathrm{ng} / \mathrm{mL}$ and $<30 \mathrm{ng} / \mathrm{mL}$; deficient: $\geq 10 \mathrm{ng} / \mathrm{mL}$ and $<20 \mathrm{ng} / \mathrm{mL}$; severely deficient: $<10 \mathrm{ng} / \mathrm{mL}$. 25(OH)D, 25-hydroxyvitamin D.

(3) the association between vitamin D deficiency and separate dimensions of SES; (4) the association between vitamin D deficiency and SES index; (5) the association between vitamin $\mathrm{D}$ severe deficiency and separate dimensions of SES; and (6) the association between vitamin D severe deficiency and SES index. In all models, vitamin D sufficiency was taken as the reference group and the potential confounding factors were adjusted.

\section{Patient and public involvement}

No patients (participants) were involved.

\section{RESULTS}

\section{Participant characteristics}

The median serum $25(\mathrm{OH}) \mathrm{D}$ level of the 1151 women of childbearing age was $20.90(13.60-34.60) \mathrm{ng} / \mathrm{mL}$. The prevalence of vitamin $\mathrm{D}$ insufficiency, deficiency and severe deficiency was $20.16 \%, 31.80 \%$ and $15.99 \%$, respectively (table 1 ).

Table 2 shows the vitamin D status by demographic characteristics, SES, nutritional supplement and utilisation of health services. Overall, $51.69 \%$ of the study population were $<28$ years old, $64.55 \%$ were of normal BMI, $78.89 \%$ were unemployed or farmers, $73.02 \%$ had junior high school or below educational attainment, $61.71 \%$ had household annual income $\geq ¥ 10000$, and $63.57 \%$ felt their household income was inadequate or deficit for expenditure.

\section{Multivariate logistic regression analysis}

Table 3 displays the results of the multivariate logistic analysis of the association between SES and vitamin D level. After adjusting for confounding factors, compared with household annual income $\geq ¥ 10000$, household annual income $<¥ 10000$ was associated with an increased risk of vitamin D insufficiency (adjusted OR (aOR): 2.10, 95\% CI 1.41 to 3.14 ), deficiency (aOR: $1.58,95 \%$ CI 1.09 to 2.29 ) as well as severe deficiency (aOR: $2.79,95 \%$ CI 1.78 to 4.38). Inadequate household income for expenditure was associated with an elevated risk of vitamin D insufficiency (aOR: $1.66,95 \%$ CI 1.08 to 2.54 ) and deficiency (aOR:
$1.81,95 \%$ CI 1.26 to 2.62$)$. Accepting physical examination during the past year was associated with a decreased risk of vitamin D deficiency (aOR: $0.49,95 \%$ CI 0.34 to 0.70 ) and severe deficiency (aOR: $0.25,95 \% \mathrm{CI} 0.15$ to $0.41)$.

In table 4, multivariate logistic regression models were performed to further explore the association between vitamin D level and SES index or health service utilisation. After adjusting for confounding factors, low SES index was associated with an increased risk of vitamin D insufficiency (aOR: $2.40,95 \%$ CI 1.52 to 3.80 ) and deficiency (aOR: 1.64, 95\% CI 1.08 to 2.50 ). Both middle and low SES index were associated with increased risk of vitamin D severe deficiency (aOR: 1.70, 95\% CI 1.02 to 2.84; aOR: $2.45,95 \%$ CI 1.45 to 4.14 ). Accepting physical examination during the past year was associated with a reduced risk of vitamin D deficiency (aOR: $0.49,95 \%$ CI 0.35 to 0.70 ) and severe deficiency (aOR: $0.24,95 \%$ CI 0.15 to 0.39 ), suggesting it is a protective factor for vitamin D deficiency.

\section{DISCUSSION}

Our study found that the prevalence of vitamin $\mathrm{D}$ insufficiency and deficiency (serum $25(\mathrm{OH}) \mathrm{D}<20 \mathrm{ng} / \mathrm{mL}$ ) among women of childbearing age who intended to become pregnant in four counties of Henan Province, China was $20.16 \%$ and $47.80 \%$, respectively. Compared with countries with similar latitude such as the USA and some other Asian countries in lower latitude such as Cambodia, the prevalence of vitamin D insufficiency in our study was lower (USA, $36 \%{ }^{30}$; Cambodia, $35.6 \%{ }^{31}$ ), but the prevalence of vitamin D deficiency was higher (USA, $42 \%^{30}$; Cambodia, $29 \%^{31}$ ). Although the prevalence of vitamin D sufficiency in our setting was much higher than the average vitamin D sufficiency in northern rural China $(20.3 \%){ }^{32}$ the medium serum $25(\mathrm{OH}) \mathrm{D}$ level was similar $\left(20.9 \mathrm{ng} / \mathrm{mL}\right.$ vs $\left.22.0 \mathrm{ng} / \mathrm{mL}^{32}\right)$, suggesting a higher rate of severely low serum $25(\mathrm{OH}) \mathrm{D}$ level in our study. In fact, the prevalence of severe vitamin D deficiency $(<10 \mathrm{ng} /$ $\mathrm{mL}$ ) in our study was $15.99 \%$, with a median of $5.63 \mathrm{ng} /$ $\mathrm{mL}$. Vitamin D deficiency among women of childbearing age in our setting is an alarming phenomenon and thus deserves attention.

After taking into consideration lifestyle and health service utilisation, we examined how separate dimensions and aggregate index of SES related to vitamin D status and found that lower income, inadequate income for expenditure and lower SES index were significantly associated with vitamin D insufficiency and deficiency, while education and occupation were not. Several pathways could explain this result. Different tendencies to sunlight exposure could be one, ${ }^{33}$ and knowledge and access to vitamin D supplement and behavioural habits could be another. ${ }^{34}$ It is worth noting that in our study physical examination during the past year was associated with a reduced risk of vitamin D deficiency, a pathway of SES to vitamin D status that was hardly noticed before. Although previous 
Table 2 Demographic, socioeconomic, nutritional, behavioural and utilisation of health service characteristics by vitamin D status

\begin{tabular}{|c|c|c|c|c|c|}
\hline & 25(OH)D level & $\begin{array}{l}\text { Sufficient } \\
(\mathrm{n}=369)\end{array}$ & $\begin{array}{l}\text { Insufficient } \\
(\mathrm{n}=232)\end{array}$ & $\begin{array}{l}\text { Deficient } \\
(\mathrm{n}=366)\end{array}$ & $\begin{array}{l}\text { Severely deficient } \\
(n=184)\end{array}$ \\
\hline Exposure variables & Median(25\%-75\%) & n (\%) & n (\%) & n (\%) & n (\%) \\
\hline \multicolumn{6}{|l|}{ Demographic variables } \\
\hline \multicolumn{6}{|l|}{ Age } \\
\hline$<28$ & $22.90(14.40-37.20)$ & $222(60.20)$ & $113(48.71)$ & $162(44.26)$ & $98(53.26)$ \\
\hline $28-$ & $19.20(13.20-31.10)$ & $147(39.80)$ & $119(51.29)^{\star \star}$ & $204(55.74)^{\star \star \star}$ & $86(46.74)$ \\
\hline$<24$ & $21.20(13.60-35.30)$ & $244(66.12)$ & $147(63.36)$ & $236(64.48)$ & $116(63.04)$ \\
\hline $24-$ & $21.80(14.40-34.50)$ & $92(24.93)$ & $58(25.00)$ & $85(23.22)$ & $44(23.91)$ \\
\hline $28-$ & $19.30(12.80-31.25)$ & $33(8.94)$ & 27 (11.64) & $45(12.30)$ & $24(13.04)$ \\
\hline \multicolumn{6}{|l|}{ Gravidity } \\
\hline No & $20.80(13.55-34.65)$ & $327(88.62)$ & 206 (88.79) & $323(88.25)$ & $165(89.67)$ \\
\hline Yes & 21.35 (14.30-34.65) & $42(11.38)$ & $26(11.21)$ & $43(11.75)$ & 19 (10.33) \\
\hline \multicolumn{6}{|l|}{ Socioeconomic status } \\
\hline \multicolumn{6}{|l|}{ Women's education } \\
\hline High school or above & $24.30(14.90-38.40)$ & $126(34.24)$ & $51(21.98)$ & $93(25.48)$ & $40(21.74)$ \\
\hline Junior high or below & $20.15(13.20-32.18)$ & $242(65.76)$ & $181(78.02)^{\star}$ & $272(74.52)^{\star}$ & $144(78.26)^{\star \star}$ \\
\hline \multicolumn{6}{|l|}{ Husband's education } \\
\hline High school or above & $22.40(14.10-37.40)$ & $128(34.69)$ & $58(25.00)$ & $103(28.14)$ & $51(21.72)$ \\
\hline Junior high or below & $20.40(13.33-32.45)$ & $241(65.31)$ & $174(75.00)^{\star}$ & $263(71.86)$ & $133(72.28)$ \\
\hline Unemployed or farmers & $23.60(12.23-32.58)$ & $157(42.78)$ & $87(37.83)$ & $132(36.26)$ & $48(26.09)^{\star \star \star}$ \\
\hline \multicolumn{6}{|c|}{ Household annual income ( $¥)$} \\
\hline$\geq 10000$ & $23.00(14.60-37.70)$ & $278(75.34)$ & $122(52.59)$ & $223(61.26)$ & $86(46.74)$ \\
\hline$<10000$ & $18.50(11.53-27.38)$ & $91(24.66)$ & $110(47.41)^{\star \star \star}$ & $141(38.74)^{\star \star \star}$ & $98(53.26)^{\star \star \star}$ \\
\hline \multicolumn{6}{|c|}{ Household income for expenditure } \\
\hline Surplus & $25.80(14.70-39.60)$ & $189(51.22)$ & $65(28.02)$ & $110(30.14)$ & 55 (29.89) \\
\hline Inadequate or deficit & $19.15(13.05-29.58)$ & $180(48.78)$ & $167(71.98)^{\star \star \star}$ & $255(69.86)^{\star \star \star}$ & $129(70.11)^{\star \star \star}$ \\
\hline \multicolumn{6}{|l|}{ SES index } \\
\hline High & $24.50(14.70-38.70)$ & $161(43.99)$ & $57(24.78)$ & $107(29.56)$ & $47(25.54)$ \\
\hline Middle & $20.50(13.30-35.10)$ & $124(33.88)$ & $71(30.87)$ & $124(34.25)$ & $64(34.78)$ \\
\hline Low & $19.90(12.95-27.90)$ & $81(22.13)$ & $102(44.35)^{\star \star \star}$ & $131(36.19)^{\star \star \star}$ & $73(39.67)^{\star \star \star}$ \\
\hline \multicolumn{6}{|l|}{ Nutritional factors } \\
\hline \multicolumn{6}{|l|}{ Nutritional supplement } \\
\hline No & $19.50(13.10-31.15)$ & $231(62.60)$ & $179(77.16)$ & $293(80.05)$ & $144(78.26)$ \\
\hline Yes & $26.30(14.88-40.33)$ & $138(37.40)$ & $53(22.84)^{\star \star \star}$ & $73(19.95)^{\star \star \star}$ & $40(21.74)^{\star \star \star}$ \\
\hline \multicolumn{6}{|l|}{ Meat intake } \\
\hline Once or more per week & $21.70(14.70-36.30)$ & $220(59.62)$ & $130(56.30)$ & $213(58.20)$ & $84(45.65)$ \\
\hline Less than once per week & $19.80(12.30-32.40)$ & $149(40.38)$ & $102(43.97)$ & $153(41.80)$ & $100(54.35)^{\star \star}$ \\
\hline
\end{tabular}


Table 2 Continued

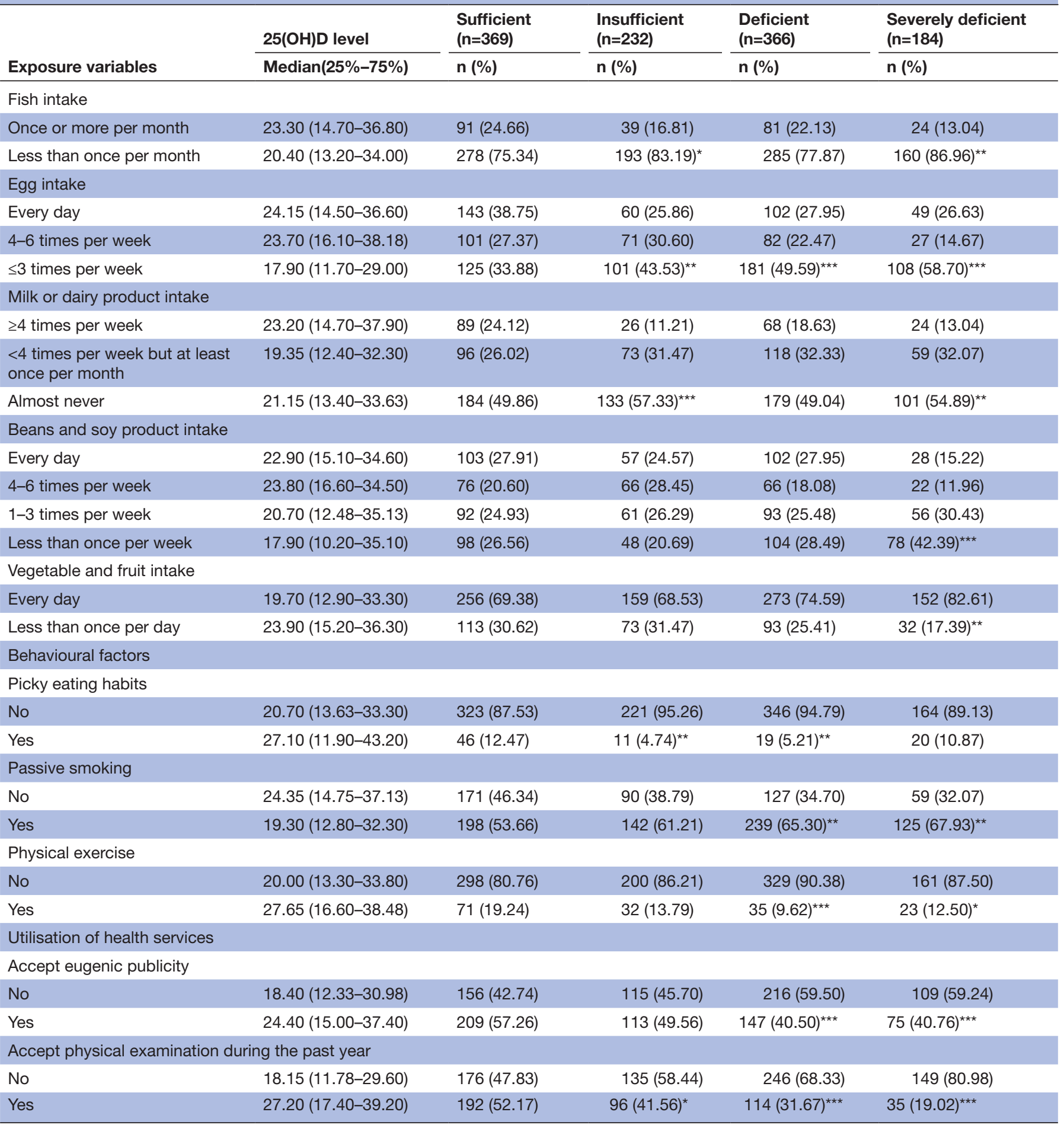

${ }^{*} \mathrm{P}<0.05$, ${ }^{* *} \mathrm{P}<0.01,{ }^{* * *} \mathrm{P}<0.001$.

BMI, body mass index; 25(OH)D, 25-hydroxyvitamin D; SES, socioeconomic status.

studies also indicated an association between SES and vitamin D status, ${ }^{30} 35-38$ our results further pointed out that, for women of childbearing age in rural northern China, a considerable association still existed even after controlling for potential mediators, namely diet and nutritional supplement, health service utilisation, physical exercise and passive smoking. Considering SES could not be a direct factor for vitamin $\mathrm{D}$ deficiency/insufficiency, there could be other mediators of SES influencing vitamin D status that need to be identified. For example, it was found that adult women with lower education level in Europe were less likely to take vitamin D supplement. ${ }^{39-41}$ Yet, until now, there have been limited studies exploring the possible ways through which different dimensions 
Table 3 Multivariate logistic analysis of the association of vitamin D status with separate socioeconomic status indicators and health service utilisation variables

\begin{tabular}{|c|c|c|c|}
\hline Vitamin D status & $\begin{array}{l}\text { Insufficiency } \\
\text { aOR }(95 \% \mathrm{Cl})^{\star}\end{array}$ & $\begin{array}{l}\text { Deficiency } \\
\text { aOR }(95 \% \mathrm{Cl})^{\star}\end{array}$ & $\begin{array}{l}\text { Severe deficiency } \\
\text { aOR }(95 \% \mathrm{Cl})^{\star}\end{array}$ \\
\hline \multicolumn{4}{|l|}{ Socioeconomic status } \\
\hline High school or above & 1.00 & 1.00 & 1.00 \\
\hline Junior high or below & $1.26(0.79$ to 2.00$)$ & $0.99(0.66$ to 1.48$)$ & $1.40(0.83$ to 2.36$)$ \\
\hline Junior high or below & $1.08(0.70$ to 1.68$)$ & $1.03(0.70$ to 1.51$)$ & $1.10(0.67$ to 1.80$)$ \\
\hline \multicolumn{4}{|l|}{ Women's occupation } \\
\hline Others & 1.00 & 1.00 & 1.00 \\
\hline Unemployed or farmers & $1.58(0.96$ to 2.61$)$ & $1.43(0.91$ to 2.24$)$ & 1.39 (0.81 to 2.40$)$ \\
\hline \multicolumn{4}{|l|}{ Household annual income ( $¥)$} \\
\hline$\geq 10000$ & 1.00 & 1.00 & 1.00 \\
\hline$<10000$ & $2.10(1.41$ to 3.14$)$ & 1.58 (1.09 to 2.29$)$ & $2.79(1.78$ to 4.38$)$ \\
\hline \multicolumn{4}{|c|}{ Household income for expenditure } \\
\hline Surplus & 1.00 & 1.00 & 1.00 \\
\hline Inadequate or deficit & 1.66 (1.08 to 2.54$)$ & 1.81 (1.26 to 2.62$)$ & $1.36(0.85$ to 2.16$)$ \\
\hline \multicolumn{4}{|l|}{ Utilisation of health services } \\
\hline \multicolumn{4}{|l|}{ Accept eugenic publicity } \\
\hline
\end{tabular}

*Adjusted for women's age, gravidity, BMI, history of chronic diseases, nutritional supplement, meat intake, egg intake, fish intake, vegetable and fruit intake, beans or bean product intake, milk or dairy product intake, picky eating habits, passive smoking and physical exercise. aOR, adjusted OR; BMI, body mass index.

and composite SES could affect vitamin D status. The mechanisms underlying the association between SES and vitamin D status need further study.

In this study, the principal component analysis was used to construct SES index. There are different ways of measuring SES in studies of vitamin D status. The most common is focusing on one dimension of SES by using individual SES indicators such as educational attainment, income, expense management and occupation. ${ }^{36} 38$ Indicators such as 'poverty-income ratio', a ratio of family income to poverty threshold used in the National Health and Nutrition Examination Survey in USA, ${ }^{42}$ also focus on one dimension of SES, that is, family income, but takes into consideration local development to create an index. ${ }^{30}$ Another way is to develop composite SES indexes with scales given to different indicators or indicator combinations. For example, the Kuppuswamy's
Socioeconomic Status, a relatively well-established tool in India, assigns 7 scores to education, 10 for occupation and 12 for family income, and makes five groups of SES. ${ }^{43}$ The SES index for the German Health Interview and Examination Survey for Adults (DEGS1) assigns different scores to different combinations of specific kinds of occupation, income and education. ${ }^{37}$ Some others developed a specific questionnaire based on local conditions to get an SES score. For instance, EPICES (Évaluation de la précarité et des inégalités de santé dans les centres d'examens de santé - Evaluation of low socio-economic status and inequalities in Health Examination Centers), a French evaluation of low SES and inequalities in health examination centres, aggregates a lot more social dimensions such as leisure activities. ${ }^{35}$ In our study, we not only evaluated several individual dimensions of SES to examine their separate associations with vitamin D deficiency/ 
Table 4 Multivariate logistic analysis of the association of vitamin D status with socioeconomic status index and health service utilisation variables

\begin{tabular}{|c|c|c|c|}
\hline Vitamin D status & $\begin{array}{l}\text { Insufficiency } \\
\text { aOR }(95 \% \mathrm{CI})^{*}\end{array}$ & $\begin{array}{l}\text { Deficiency } \\
\text { aOR }(95 \% \mathrm{Cl})^{*}\end{array}$ & $\begin{array}{l}\text { Severe deficiency } \\
\text { aOR }(95 \% \mathrm{Cl})^{\star}\end{array}$ \\
\hline \multicolumn{4}{|c|}{ Socioeconomic status } \\
\hline \multicolumn{4}{|l|}{ SES index } \\
\hline High & 1.00 & 1.00 & 1.00 \\
\hline Middle & 1.26 (0.80 to 1.99$)$ & 1.23 (0.82 to 1.82$)$ & 1.70 (1.02 to 2.84$)$ \\
\hline Low & $2.40(1.52$ to 3.80$)$ & 1.64 (1.08 to 2.50$)$ & $2.45(1.45$ to 4.14$)$ \\
\hline \multicolumn{4}{|c|}{ Utilisation of health services } \\
\hline \multicolumn{4}{|c|}{ Accept eugenic publicity } \\
\hline No & 1.00 & 1.00 & 1.00 \\
\hline Yes & 0.94 (0.64 to 1.40$)$ & 0.77 (0.54 to 1.11$)$ & $1.10(0.70$ to 1.72$)$ \\
\hline \multicolumn{4}{|c|}{ Physical examination during the past year } \\
\hline No & 1.00 & 1.00 & 1.00 \\
\hline Yes & 0.74 (0.50 to 1.09$)$ & $0.49(0.35$ to 0.70$)$ & $0.24(0.15$ to 0.39$)$ \\
\hline
\end{tabular}

*Adjusted for women's age, gravidity, BMI, history of chronic diseases, nutritional supplement, meat intake, egg intake, fish intake, vegetable and fruit intake, beans or bean product intake, milk or dairy product intake, picky eating habits, passive smoking and physical exercise. aOR, adjusted OR; BMI, body mass index; SES, socioeconomic status.

insufficiency, but also constructed an SES index. Since there is no well-recognised method of measuring SES in local setting and there seems to be lack of credibility in arbitrarily assigning scores to different SES dimensions, the principal component analysis we used was a 'datadriven' one and thus could avoid subjective judgement to some extent. Although hardly seen in analysing vitamin D status, principal component analysis has proven to be quite validated and robust in constructing SES in other epidemiological studies. ${ }^{27}$ By summing the effects of individual SES indicators, we could get a better view of the association between SES and vitamin D insufficiency/ deficiency and increase the test power.

Suggesting a pervasive vitamin D insufficiency/deficiency and health inequalities in vitamin $\mathrm{D}$ status among women of childbearing age in rural China, our findings call for attention paid to this population. Maternal vitamin D deficiency/insufficiency not only has adverse health effects on the mothers themselves, but also means their fetus will develop in a low vitamin D state. ${ }^{13}$ It remains inconclusive whether this influence on the fetus acts in the later stage of pregnancy or throughout the whole gestational process, but it is very likely that maternal vitamin $\mathrm{D}$ begins its vital role in fetal development in the early stage of pregnancy because $1,25(\mathrm{OH}) 2 \mathrm{D}$ induces decidualisation, which is key to implantation, ${ }^{13}$ and early pregnancy is the stage when growth trajectory is set and bone development starts. ${ }^{14}$ Some studies did find an association between maternal vitamin $\mathrm{D}$ status in early pregnancy and fetal and neonatal growth. ${ }^{14}$ Nevertheless, vitamin D deficiency/insufficiency in women of childbearing age is quite universal and vitamin $\mathrm{D}$ level is found to be lower in early pregnancy than in later pregnancy and in non-pregnant women than in pregnant ones. ${ }^{44}$
Initiating vitamin D supplementation before pregnancy could help guarantee a sufficient serum $25(\mathrm{OH}) \mathrm{D}$ level at the early stage of pregnancy. It is of importance to narrow down social inequalities and to provide support to women of lower SES, who are often found to be less educated, poorer, more obese, more likely to currently smoke, more physically inactive and less likely to frequently drink milk. $^{44}$

There are some strengths to our study. The data were representative and were of a large sample size, with high measurement accuracy and good quality control. Information on main exposures and blood sample was obtained at the same time to minimise recall bias. In addition, separate dimensions of SES and the SES index were both taken to comprehensively explore the associations between SES and vitamin D status and the potential underlying mechanisms. The SES index was constructed using principal component analysis to aggregate over education and occupation of women's and their husbands, household income and expenditure, avoiding the potential bias that might be brought about by a single indicator and thus improving test power and reliability. What is more, compared with previous studies, which were mainly descriptive, our study adopted multivariate logistic regression analyses to adjust for many potential confounding and mediating factors, including diet and nutrition, physical exercise, passive smoking and public health service utilisation, helping to better identify how SES was associated with vitamin D status.

There are also limitations to the study. The level of serum 25(OH)D might be underestimated because blood samples were collected in winter (December, January and February), when daylight and temperature were lower compared with summer. Fortunately, it might not 
affect the estimation of the associations between SES and vitamin D status since the collection of blood samples and the interviews about exposure factors were conducted at the same time and thus the season could not be a confounding factor. Due to limited data, family assets and living conditions, which were also usual indicators of SES, were not included in our analysis. However, considering family income and expenditure are thought to be a more reliable measure of $\mathrm{SES}^{28}$ and can largely reflect family wealth, and because income, education, and occupation and employment are the more widely used indicators of SES in epidemiological studies ${ }^{45}$ than assets and living conditions, this limitation would not change our conclusion. Also, due to limited data, we were not able to obtain data on sunlight exposure of every participant, which could be an important mediating factor in our analysis. Furthermore, since there are currently no general standards for 25(OH)D measurements in China, the laboratory did not participate in any vitamin $\mathrm{D}$ standardisation programme or use standardisation of $25(\mathrm{OH}) \mathrm{D}$ measurements, which might affect comparison between the present study and other studies.

In conclusion, vitamin D deficiency/insufficiency was quite common among women of childbearing age in rural northern China. Lower SES was remarkably associated with increased risk of vitamin D deficiency/insufficiency. The underlying mechanisms could be nutritional and behavioural factors and utilisation of public health services, but there might be other pathways that need to be identified. It is suggested that more efforts should be given to improving the nutritional status and health education of women of childbearing age and equalities in healthcare services in order to change their current state of vitamin D deficiency/insufficiency.

\section{Author affiliations}

${ }^{1}$ Institute of Population Research/China Center on Population Health and

Development, Peking University, Beijing, China

${ }^{2}$ National Health Commission Key Laboratory of Birth Defects Prevention, Henan Key Laboratory of Population Defects Prevention, Zhengzhou, Henan, China

Contributors SL, LJ and YZ conducted the analysis and interpretation of data, drafted the work, and reviewed and revised it. LP and XS conceptualised and designed the study and the project where the data came from, coordinated and supervised data collection, and critically reviewed and revised the manuscript for important intellectual content. JL and JC designed the data collection instruments, acquired the data and revised the paper critically for important intellectual content. All authors have approved the final manuscript as submitted and agreed to be accountable for all aspects of the work in ensuring that questions related to the accuracy or integrity of any part of the work were appropriately investigated and resolved.

Funding This study was supported by the National Key Research and Development Program of China (2018YFC1004303); National Natural Science Foundation of China (41871360); Danone Institute China Diet Nutrition Research \& Communication Grant (DIC2015-05); and National Health Commission Key Laboratory of Birth Defects Prevention, Henan Province (ZD202002).

Competing interests None declared.

Patient and public involvement Patients and/or the public were not involved in the design, or conduct, or reporting, or dissemination plans of this research.

Patient consent for publication Not required.
Ethics approval The study was approved by the Institutional Review Board of Peking University Health Science Center (IRB00001052-08083).

Provenance and peer review Not commissioned; externally peer reviewed.

Data availability statement Data are available upon reasonable request.

Open access This is an open access article distributed in accordance with the Creative Commons Attribution Non Commercial (CC BY-NC 4.0) license, which permits others to distribute, remix, adapt, build upon this work non-commercially, and license their derivative works on different terms, provided the original work is properly cited, appropriate credit is given, any changes made indicated, and the use is non-commercial. See: http://creativecommons.org/licenses/by-nc/4.0/.

ORCID iD

Shiqi Lin http://orcid.org/0000-0003-1874-5900

\section{REFERENCES}

1 Schöttker B, Ball D, Gellert C, et al. Serum 25-hydroxyvitamin D levels and overall mortality. A systematic review and meta-analysis of prospective cohort studies. Ageing Res Rev 2013;12:708-18.

2 Zhang W, Stoecklin E, Eggersdorfer M. A glimpse of vitamin D status in mainland China. Nutrition 2013;29:953-7.

3 Lu Y, Liu M, Pei Y, et al. Low levels of serum 25-hydroxyvitamin $\mathrm{D}$ and risk of metabolic syndrome in China. Int J Clin Exp Med 2015;8:13790-6.

4 Xiao Y, Wei L, Xiong X, et al. Association between vitamin D status and diabetic complications in patients with type 2 diabetes mellitus: a cross-sectional study in Hunan China. Front Endocrinol 2020;11:564738.

5 Jiang X, Peng M, Chen S, et al. Vitamin D deficiency is associated with dyslipidemia: a cross-sectional study in 3788 subjects. Curr Med Res Opin 2019;35:1059-63.

6 Wang $\mathrm{T}$, Sun $\mathrm{H}, \mathrm{Ge} \mathrm{H}$, et al. Association between vitamin $\mathrm{D}$ and risk of cardiovascular disease in Chinese rural population. PLOS One 2019;14:12.

7 Wang X, Jiao X, Xu M, et al. Effects of circulating vitamin D concentrations on emotion, behavior and attention: a cross-sectional study in preschool children with follow-up behavior experiments in juvenile mice. J Affect Disord 2020;275:290-8.

8 Yao Y, Fu S, Zhang H, et al. The prevalence of depressive symptoms in Chinese longevous persons and its correlation with vitamin D status. BMC Geriatr 2018;18:7.

9 Chen Y, Liu D, Zeng L, et al. Effect of serum 25-hydroxyvitamin $\mathrm{D}$ levels on sperm quality and assisted reproductive technology outcomes for men of infertile Chinese couples. Andrology 2020;8:1277-86.

10 Chen $\mathrm{C}$, Zhai H, Cheng J, et al. Causal link between vitamin D and total testosterone in men: a Mendelian randomization analysis. $J$ Clin Endocrinol Metab 2019;104:3148-56.

11 Wang Y, Li H, Zheng M, et al. Maternal vitamin D deficiency increases the risk of adverse neonatal outcomes in the Chinese population: a prospective cohort study. PLoS One 2018;13:e0195700.

12 Al-Shafei Al, Rayis DA, Mohieldein AH. Maternal early pregnancy serum level of 25-hydroxyvitamin $D$ and risk of gestational diabetes mellitus. Int J Gynecol Obstet; 4 .

13 Shin JS, Choi MY, Longtine MS, et al. Vitamin D effects on pregnancy and the placenta. Placenta 2010;31:1027-34.

14 Leffelaar ER, Vrijkotte TGM, van Eijsden M. Maternal early pregnancy vitamin $D$ status in relation to fetal and neonatal growth: results of the multi-ethnic Amsterdam born children and their development cohort. Br J Nutr 2010;104:108-17.

15 Wang S, Shen G, Jiang S, et al. Nutrient status of vitamin D among Chinese children. Nutrients 2017;9:319.

16 Wang J, Zhang JY, Wei R, et al. Serum 25 hydroxyvitamin D status in 6-Month-Old infants in Guangzhou, China: a paired longitudinal follow up study. Matern Child Nutr 2020;16:9.

17 Wei F, Wang Z, Wang J, et al. Serum vitamin D levels among children aged $0-12$ years in the first affiliated hospital of Harbin medical university, China. J Public Health 2018;40:721-6.

18 Holick MF. Vitamin D deficiency. N Engl J Med Overseas Ed 2007;357:266-81.

19 El-Hajj Fuleihan G, Nabulsi M, Choucair M, et al. Hypovitaminosis D in healthy schoolchildren. Pediatrics 2001;107:E53.

20 Javaid W, Sarwar A, Tariq H. Prevalence of vitamin D deficiency and insufficiency in the paediatric population of Punjab, Pakistan. Indo American Journal of Pharmaceutical Sciences 2019;6:11884-8.

21 Maddah M, Sharami SH, Neyestani TR. Vitamin D insufficiency among postmenopausal women in urban and rural areas in Guilan, Northern Iran. J Nutr Elder 2009;28:386-93. 
22 Islam MZ, Lamberg-Allardt C, Kärkkäinen M, et al. Vitamin D deficiency: a concern in premenopausal Bangladeshi women of two socio-economic groups in rural and urban region. Eur J Clin Nutr 2002:56:51-6.

23 Gannagé-Yared M-H, Maalouf G, Khalife S, et al. Prevalence and predictors of vitamin $D$ inadequacy amongst Lebanese osteoporotic women. Br J Nutr 2009;101:487-91.

24 Darmon N, Drewnowski A. Does social class predict diet quality? Am J Clin Nutr 2008;87:1107-17.

25 Arneson WL, Arneson DL. Current methods for routine clinical laboratory testing of vitamin D levels. Lab Med 2013;44:e38-42.

26 Holick MF, Binkley NC, Bischoff-Ferrari HA, et al. Evaluation, treatment, and prevention of vitamin D deficiency: an endocrine Society clinical practice guideline. J Clin Endocrinol Metab 2011:96:1911-30.

27 Vyas S, Kumaranayake L. Constructing socio-economic status indices: how to use principal components analysis. Health Policy Plan 2006;21:459-68.

28 McKenzie DJ. Measuring inequality with asset indicators. J Popul Econ 2005;18:229-60.

29 Qin Y, Melse-Boonstra A, Pan X, et al. Anemia in relation to body mass index and waist circumference among Chinese women. Nutr $J$ 2013;12:10.

30 Ginde AA, Sullivan AF, Mansbach JM, et al. Vitamin D insufficiency in pregnant and nonpregnant women of childbearing age in the United States. Am J Obstet Gynecol 2010;202:436.e1-436.e8.

31 Smith G, Wimalawansa S, Laillou A, et al. High prevalence of vitamin $\mathrm{D}$ deficiency in Cambodian women: a common deficiency in a sunny country. Nutrients 2016;8:290

32 Liu X, Zhang Y, Mao D, et al. [Serum vitamin D levels of Chinese rural women of childbearing age in 2010-2012]. Wei Sheng Yan Jiu 2017;46:367-72.

33 Hunt-Watts HJ, Cade JE, Hadley DM. Food and nutrient intake in low-income families: the archaeology of nutrition. Proceedings of the Nutrition Society 2015;74:E356-8.

34 Calvo MS, Whiting SJ, Barton CN. Vitamin D fortification in the United States and Canada: current status and data needs. Am J Clin Nutr 2004;80:1710S-6.
35 Léger-Guist'hau J, Domingues-Faria C, Miolanne M, et al. Low socio-economic status is a newly identified independent risk factor for poor vitamin D status in severely obese adults. J Hum Nutr Diet 2017;30:203-15.

$36 \mathrm{Kim} \mathrm{J}-\mathrm{S}$. Factors associated with vitamin D status among Korean female adolescents. J Pediatr Nurs 2019;44:e79-83.

37 Rabenberg M, Scheidt-Nave C, Busch MA, et al. Vitamin D status among adults in Germany--results from the German Health Interview and Examination Survey for Adults (DEGS1). BMC Public Health 2015;15:641.

38 Wyskida M, Owczarek A, Szybalska A, et al. Socio-Economic determinants of vitamin $D$ deficiency in the older Polish population: results from the PolSenior study. Public Health Nutr 2018;21:1995-2003.

39 Knapik A, Kocot K, Witek A, et al. Dietary supplementation usage by pregnant women in Silesia - population based study. Ginekol Pol 2018;89:506-12.

40 Novaković R, Cavelaars A, Geelen A, et al. Socio-Economic determinants of micronutrient intake and status in Europe: a systematic review. Public Health Nutr 2014;17:1031-45.

41 McCartney DMA, Younger KM, Walsh J, et al. Socio-Economic differences in food group and nutrient intakes among young women in Ireland. Br J Nutr 2013;110:2084-97.

42 Centers for Disease Control and Prevention (CDC) NCfHSN. National health and nutrition examination survey data. In: Hyattsville MUDoHaHS, editor, 2009.

43 Sathish P, Sajeethakumari R, Padma R, et al. Correlation between maternal and neonatal blood vitamin $\mathrm{D}$ levels and its effect on the newborn anthropometry. Int J Reprod Contracept Obstet Gynecol 2016:2983-8.

44 Liu X, Baylin A, Levy PD. Vitamin D deficiency and insufficiency among US adults: prevalence, predictors and clinical implications. $\mathrm{Br}$ J Nutr 2018;119:928-36.

45 Kaplan GA, Keil JE. Socioeconomic factors and cardiovascular disease: a review of the literature. Circulation 1993;88:1973-98. 